\title{
The Role of National Culture in Advertising's Sensitivity to Business Cycles: An Investigation across Continents
}

\author{
Barbara Deleersnyder \\ Marnik G. Dekimpe \\ Jan-Benedict E.M. Steenkamp \\ Peter S.H. Leeflang*
}

September 4, 2008

Barbara Deleersnyder is Assistant Professor of Marketing, Tilburg University (E-mail:

b.deleersnyder@uvt.nl). Marnik G. Dekimpe is Research Professor of Marketing \& CentER Fellow at Tilburg University, and Professor of Marketing at the Catholic University Leuven (E-mail: m.g.dekimpe@uvt.nl). Jan-Benedict E.M. Steenkamp is C. Knox Massey Distinguished Professor of Marketing and Marketing Area Chair, Kenan-Flagler Business School, University of North Carolina at Chapel Hill (E-mail: JBS@unc.edu). Peter S.H. Leeflang is The Frank M. Bass Professor of Marketing, University of Groningen (E-mail: p.s.h.leeflang@rug.nl). 
* We thank TNS for providing U.S. advertising data. The assistance of Richard Herbert (Europanel) is especially acknowledged. The authors also thank Kris Helsen for his help in acquiring information on the introduction date of commercial television, and Financial support by the Flemish Science Foundation (F.W.O.) under Grant No. G.0116.04 is greatly appreciated. 


\title{
The Role of National Culture in Advertising's Sensitivity to Business Cycles: An Investigation across Continents
}

\begin{abstract}
We conduct a systematic investigation into the cyclical sensitivity of advertising expenditures in 37 countries across all continents, covering up to 25 years and four key media: magazines, newspapers, radio and television. We show that advertising is considerably more sensitive to business-cycle fluctuations than the economy as a whole, the average co-movement elasticity being 1.4. Advertising behaves less cyclically in countries high on long-term orientation and power distance, while advertising is more cyclical in countries high on uncertainty avoidance. Further, advertising is more sensitive to the business cycle in countries characterized by significant stockmarket pressure and few foreign-owned multinationals. We provide initial evidence on the long-run social and managerial losses incurred when companies tie ad spending too tightly to business cycles. Countries where advertising behaves more cyclically exhibit slower growth of the advertising industry - an important industry in its own right, and a major employer of marketing practitioners. Moreover, private-label growth is higher in countries characterized by more cyclical advertising spending, implying significant losses for brand manufacturers. Finally, an examination of 26 global companies shows that stock-price performance is lower for companies that exhibit stronger pro-cyclical advertising spending patterns.
\end{abstract}

Key words: Advertising, business cycle, time-series econometrics, cross-country comparison, national culture, stock-price performance, private label, international marketing. 
Advertising is arguably the most visible, and also one of the most important, marketing instruments. While there exists an impressive body of research on advertising at the micro (company) level, much less is known about advertising at the macro (country) level. Conventional wisdom holds that advertising is among the marketing instruments most affected by general economic conditions. Every time the economy enters a downturn, advertising budgets seem to be among the first to be cut (Dobbs, Karakolev, and Malige 2002). A widespread reduction in advertising activity by many companies during a recession translates into a considerable drop in a country's aggregate advertising spending. In the recession year 2001, for instance, U.S. ad spending fell by $9.4 \%$, the biggest decline since 1938 . On the other hand, when the economy goes up, advertising expenditure is thought to accelerate. To illustrate, in the expansion year 2004, growth in advertising spending in the U.K. was close to 5\% (WARC 2005).

Against this background, advertising executives have repeatedly claimed that counter-cyclical, or at least inelastic, advertising may be more effective than pro-cyclical, elastic advertising (Frankenberger and Graham 2003; O’Toole 1991). Hence, why do we (still) observe such highlycyclical advertising behavior? Is this behavior limited to the U.S., or is it generalizable across countries? Why might companies in different countries respond differently to business cycles? And finally, are there managerial or social losses when ad spending is tied too tightly to business cycles?

The purpose of this study is to address these questions. We investigate whether the anecdotal evidence on pro-cyclical advertising spending generalizes across countries, and what factors underlie the cross-national variation (if any) in this behavior. We assess empirically the consequences of pro-cyclical behavior for both society at large and for branded-goods companies. First, we study the impact on the growth of the advertising industry - an important industry in its own right as well as an employer of many marketing practitioners. For the branded-goods companies, we quantify the effect of such pro-cyclical behavior on the growth of both aggregate private-label share and companies' stock prices. 
In combination, our results show that adjusting advertising in response to economic conditions is a behavior that generalizes across 37 countries across all inhabited continents, even though we observe large differences across countries and media. Interestingly, advertising's cyclical dependence is systematically related to the national-cultural context in which companies operate. Moreover, we show that the losses incurred when companies tie their ad spending closely to the business cycle extend far beyond the recession period, in that they affect the long-term growth of the advertising industry, private-label share, and stock prices.

\section{PREVIOUS RESEARCH ON ADVERTISING CYCLICALITY}

There exists a body of research that examines the impact of macro-economic fluctuations (typically captured through changes in a country's real GDP) on aggregate advertising spending. A first stream of research has linked the growth rate in advertising with the growth rate of the economy by first-differencing the time series (Ashley, Granger, and Schmalensee 1980; Didow and Franke 1984). However, the first-difference operator emphasizes short-run fluctuations in the series (see e.g., Baxter 1994, p. 14). Other studies have looked for a long-run equilibrium relationship between aggregate advertising and the economy through cointegration testing (Chowdhury 1994; Jung and Seldon 1995). Cointegration models test for common stochastic trends in the series, and are especially relevant to quantify a long-term equilibrium relationship among the variables.

These studies have provided valuable insights into advertising's sensitivity to macro-economic factors. However, they suffer from several limitations that constitute an impetus for the present study. First, previous research is limited in geographical scope, having typically focused on either the U.S. (e.g., Jung and Seldon 1995) or the U.K. (e.g., Turner 2000). Although these are important advertising markets, it is not obvious that results obtained for these economies are universally applicable, given growing evidence that managerial decision making is often affected by the cultural context in which managers operate (Hofstede 2001; Schneider and Barsoux 2002). As stated by Hofstede (1994, p. 4): “... the culture of the human environment in which an organization 
operates affects the management processes.” This raises the question whether particular cultural settings encourage companies to react more or less to changes in the economy.

A second limitation is the length of the time series in prior marketing research with a businesscycle lens. Given the length of business cycles, data are needed that span several decennia to avoid drawing inferences driven by the idiosyncrasies of a specific expansion or recession period. For example, Lamey et al. (2007) illustrate the cyclical sensitivity of advertising spending by comparing, for 10 top brands in the U.K., the yearly average growth in the expansion period 19971998 with the contraction period 2001-2002. It is not clear whether the observed patterns are idiosyncratic to that period and/or country.

Third, business cycles typically last between 1.5 and 8 years (Christiano and Fitzgerald 1998). Hence, neither first-differencing nor cointegration studies on annual data are well suited to study the business-cycle relationship of advertising, where fluctuations occur at a pace somewhere in between that of the short and the long run. ${ }^{1}$ This concern is exacerbated by recent work showing that the extent of association between time series may differ depending on the periodicity of the data one focuses on (Bronnenberg, Mela, and Boulding 2006; Lemmens et al. 2007).

A fourth limitation is that most prior macro-advertising studies only examined total advertising (see e.g., Chowdhury 1994; Quarles and Jeffres 1983). As discussed in Didow and Franke (1984), not all media may be equally affected by economic expansions and contractions, calling for a more disaggregate analysis. Other studies, in contrast, considered only one or two media, as television and press in Turner (2000) or newspapers in Roark and Stone (1994).

Our study addresses these limitations by studying advertising's sensitivity to business cycles (i) across 37 countries, from all continents, accounting for about 5 out of every 6 advertising dollars spent worldwide (WARC 2005), (ii) over a time span of about two decades, allowing for multiple

\footnotetext{
1 With yearly data, first differencing emphasizes variation at a periodicity of around 2 years (Baxter 1994), while cointegration testing focuses on the nature of the relationship between the very long movements in the series (i.e. with a periodicity longer than 8 year).
} 
business cycles to occur, (iii) using filtering techniques specifically developed to study businesscycle fluctuations, which are distinct from short-run associations and long-run equilibria, and (iv) for four key media separately - magazines, newspapers, radio, and television. The broad sample of country and media combinations across multiple expansion and contraction periods allows us to derive empirical generalizations on the cyclical sensitivity of advertising, and to test various hypotheses on drivers of the cross-country variability.

\section{FRAMEWORK AND HYPOTHESES}

\section{Cyclical Sensitivity of Advertising Expenditures}

Informal observation of firm behavior suggests that in times of economic adversity, many firms cut back on their advertising expenditures. At the macro level, aggregated across all firms active in a country, this is reflected in pro-cyclical advertising expenditure, moving in the same direction as the aggregate business cycle. When sales are declining, managers feel a strong need to produce results fast. After all, they tend to be compensated for meeting short-run sales targets (Abraham and Lodish 1993). Due to the lower instantaneous return from advertising versus promotions, managers may find it hard to justify large advertising investments during harsh economic times (Mela, Jedidi, and Bowman 1998). Moreover, the number of firms that advertise goes down during contraction periods due to an increased number of bankruptcies and reorganizations (Picard and Rimmer 1999). The reverse holds in economic expansions. Managers can then "afford" a longer-term view as sales are expanding, and more new firms enter the market.

While there seems to be a general consensus on the direction of advertising changes in relation to business cycle ups and downs, there is much more ambiguity about the magnitude of these changes. At first sight, one might argue that advertising expenditures are elastic, since they are more easily ramped up or cut than other company outlays (e.g., R\&D or labor). Especially when both the average advertising spending level per firm and the number of firms that advertise are shrinking, we expect an even larger reduction in aggregate advertising expenditures to follow. 
However, there are indications that inelastic - or even counter-cyclical - advertising is associated with superior firm performance, especially in recessions (Frankenberger and Graham 2003; Srinivasan, Rangaswamy, and Lilien 2005). Further, inelastic advertising can be used to reduce the volatility of the company's cash flow, which is valued by the financial markets (Srivastava, Shervani, and Fahey 1998). If more firms become guided by these insights, aggregate advertising expenditure should be relatively inelastic with respect to business-cycle fluctuations. Thus far, no study has quantified the actual extent of advertising's cyclical sensitivity.

\section{National Culture and Advertising Decisions}

We propose that national culture influences advertising decisions through: (i) managers' view on the role of advertising per se in a company's strategy, and (ii) the decision process through which the advertising budget is set.

Advertising as expense versus advertising as investment. Two views on advertising are “advertising as expense" and "advertising as investment” (Danaher and Rust 1994; White and Miles 1996). When advertising is treated as an expense, it is intended to generate returns in the short run. Advertising is then considered a component of a single period's business cost, incurred to lift shortterm sales. When unfavorable income prospects make consumers less inclined to buy (especially advertised) manufacturer brands (Lamey et al. 2007), cutting down on advertising is considered a rational strategy. Viewing advertising as an expense makes it a discretionary outlay that can be reduced easily during harsh economic times. Companies can easily postpone advertising activities during an economic contraction, while advertising is increased again when the economy improves.

The alternative view is to regard advertising as an investment, to be built up and amortized over the long run. The multi-period effect derived from ad campaigns and the general objective of increasing the stock of an organization's intangible assets are congruent with treatment of advertising as an investment in solid future performance (White and Miles 1996). To build advertising goodwill, advertising effort must be continued for a protracted period of time in order to change consumers' 
brand attitude and behavior. The outlook of positive future cash flows makes advertising decisions less dependent on the temporary uncertainty surrounding a recession. Consequently, we expect less cyclical dependence when advertising is viewed as investment than when it is viewed as an expense.

The advertising decision process. Despite the increasing trend towards sophisticated advertising models and the growing realism of quantitative techniques for setting and allocating advertising budgets, firms' advertising decisions remain subject to social influences (Low and Mohr 1999). "Information Cascades" theory builds on the notion of social processes to explain why managers often mimic the opinion and behavior of others (even if they are mistaken), rather than conducting de facto a careful, independent evaluation of alternatives when making decisions (Bikhchandani, Hirshleifer, and Welch 1992). This theory shows that herding behavior, where individuals rely on signals and information conveyed by the behavior of others, can be rational when gathering information is costly. Herding could lead managers to imitate the advertising behavior they observe from or expect of (due to over-time experience) their competitors during contraction and expansion periods (Saunders et al. 2000). Given the dictum "better be safe than sorry," potential career sanctions on deviating mistakenly from others' advertising behavior may induce more managers to decrease advertising during tough economic times and to expand advertising when most other firms do (Barwise 1999). As such, they may imitate the heuristics that other firms use, such as a percentage-of-sales decision rule (Danaher and Rust 1994), instead of conducting a formal and independent analysis. This assumes that a common reaction of managers is to reduce advertising expenditure during difficult economic times. While there is no strong academic evidence, anecdotal evidence suggests this is a reasonable assumption, even today. For example, in response to the 2008 downturn in the economy, the Financial Times (2008, p. 3) writes "Advertising is one of the first areas of expenditure to be cut in an economic downturn," and The Economist (2008, p. 61) notes that advertising is one of the first things "companies decide to cut when faced with slowing sales". 
The result of these processes would be that advertising closely follows the economic cycle, and can explain why firms' herding behavior can be rational and may dominate the advertising decision process in response to alternative economic conditions. However, the limited amount of original information underlying cascades makes them fragile (Bikhchandani, Hirshleifer, and Welch 1992), and advertising adjustments triggered by herding behavior are expected to be more volatile than adjustments based on managers' own thoughtful evaluation.

In contrast, under conditions of weak social influence, people may dare to challenge the majority position, and raise issues that contradict majority thinking (Tan et al. 1998). Such an environment promotes more strategic advertising decisions that go against the dominant response of adjusting advertising activities in the same direction as the aggregate economy.

\section{The Effects of National Culture on the Cyclical Sensitivity of Advertising Expenditures}

We use the aforementioned two mechanisms to understand how the national culture of a country can moderate advertising's sensitivity to the business cycle. We adopt Hofstede's (2001) well-known framework to operationalize culture. Hofstede identified five cultural dimensions that constitute the fundamental value orientations underlying differences in managerial practices, organizational patterns, and decision making. Four of these dimensions appear to be especially pertinent to understand cross-national variation in advertising sensitivity to business cycles: longterm orientation, power distance, uncertainty avoidance, and individualism/collectivism. ${ }^{2}$ Specifically, we expect a basic congruence between long-term orientation and power distance, and the strategic view on advertising as long-term investment, as well as a fundamental congruence between uncertainty avoidance and collectivism, and herding mentality.

Advertising as long-term investment. Managers in cultures high on long-term orientation are relatively more focused on building strong positions in their markets than on short-term

\footnotetext{
${ }^{2}$ We found neither theoretical support nor empirical evidence in our data to include the fifth Hofstede dimension, masculinity/femininity.
} 
profitability. "Persistence" is a key word describing the long-term cultural orientation - persistence in achieving one's goals, more or less irrespective of fluctuations in the environment (Hofstede 2001, p. 360). Advertising is a strategic instrument, much more suited to strengthen long-term brand equity and profits than short-term sales (Danaher and Rust 1994). Managers in long-termoriented cultures will value advertising's long-term brand building potential relatively more than managers in short-term-oriented cultures. They will be more prone to regard advertising outlays as an investment in future profits, rather than an expense to be recouped in the short term. Managers in these cultures should therefore be less inclined to let advertising decisions be dictated by fluctuations in the economic environment. Managers in cultures with a short-term orientation tend to have a rather different view. Economic fluctuations that affect the bottom line demand immediate action that generates quick results. As observed by Hofstede (2001, p. 361): "In shortterm-oriented cultures, the "bottom line" (the results of the past month, quarter, year) is a major concern; control systems are focused on it and managers are constantly judged by it." In such cultures, advertising outlays are more likely to be seen as an expense that should be modified as dictated by short-run considerations.

Power distance refers to the "extent to which the less powerful members of institutions and organizations within a country expect and accept that power is distributed unequally" (Hofstede 2001, p. 98). Cultures characterized by high power distance tend to emphasize social class. Social consciousness is high, and consumers are motivated by the need to signal the class to which they belong or to which they aspire (Roth 1995). In our hypersignified society, brands have become major conduits with which to express class differences and social aspirations. Advertising is a key instrument to build brand image. In high power distance societies, advertising will be regarded more often as a long-term strategic investment in enduring brand equity, regardless of economic conditions. We therefore hypothesize: 
H1: Advertising expenditure is less sensitive to business-cycle fluctuations in countries with a cultural long-term orientation.

H2: Advertising expenditure is less sensitive to business-cycle fluctuations in countries high on cultural power distance.

Herding mentality. The national-cultural dimensions of uncertainty avoidance and collectivism have implications for herding behavior by managers. Uncertainty avoidance refers to the degree to which societies feel threatened by uncertain, risky, ambiguous or undefined situations, and the extent to which they try to avoid such situations by adopting strict codes of behavior. Managers in high uncertainty-avoidance cultures will be more focused on risk avoidance and risk reduction than managers living in countries that are low on uncertainty avoidance (Hofstede 2001). Herding behavior is a well-known strategy to manage uncertain situations. Just as "one cannot be fired for purchasing IBM," regardless of performance, managers can hardly be blamed if they react in the same way to changing environmental circumstances as others do (Steenkamp et al. 2005). This creates herding behavior, referred to by Saunders et al. (2000) as "Lemmus Lemmus," which exacerbates cyclical swings in advertising during up- and downturns.

Individualism/collectivism pertains to the degree to which people in a country prefer to act as individuals rather than as members of society. Collectivistic societies are other-focused and emphasize conformity. Cultural collectivism emphasizes that people, including managers, are embedded in a society and unilateral actions by individuals that threaten to disrupt social consensus and established ways are frowned upon (Smith and Schwartz 1997). Managers in collectivistic societies may find intellectual support in recent insights on "the wisdom of the crowds" (Surowiecki 2004). We speculate that such herding behavior causes advertising to follow business cycles more closely. As such, we postulate:

H3: Advertising expenditure is more sensitive to business-cycle fluctuations in countries high on cultural uncertainty avoidance.

H4: Advertising expenditure is more sensitive to business-cycle fluctuations in countries high on cultural collectivism. 


\section{Control Variables}

Although our primary focus is on the influence of national-cultural factors on managers' advertising response to business cycles' ups and downs, we control for several key factors related to a country's economic structure. Listed firms experience strong pressure to fulfill the short-term (quarterly) expectations of the stock market. Consequently, they suffer from short-sightedness ('investment myopia') and (over)emphasize short-term profits (Jacobson and Aaker 1993). During contractions, their managers are more likely to favor promotional activities to maintain their bottom line, while discouraging investments in long-term brand-building activities (Mizik and Jacobson 2007). Moreover, the stock market exacerbates bankruptcy risk (Jensen and Meckling 1976). All these factors should contribute to making advertising more cyclically dependent in countries where the stock market plays a larger role in economic life.

Part of the total advertising in a country is done by foreign firms, which are less dependent on local economic conditions (Hess and Shin 1997). Moreover, our treatment implicitly assumes that advertising decisions are made by managers of the country in question. This makes sense for local companies, but in case of foreign companies, decisions on local advertising budgets may be influenced, if not directed, by foreign headquarters (Carlin, Charlton, and Mayer 2007). Hence, advertising's cyclical dependence may differ when more foreign-owned multinationals are present.

We also control for the real per capita income of a country's citizens. It is customary to control for this variable in country-level analyses as it is an indicator of various economicinstitutional factors. It also has a direct impact on the extent to which the population is able to purchase advertised brands - both during prosperous and adverse economic times - and the extent to which they have access to advertising media.

\section{METHODOLOGY}

To arrive at empirical generalizations concerning advertising's sensitivity to business cycles and to test our hypotheses, we proceed in three steps. First, we extract the cyclical component in 
each series using a business-cycle filter. Next, we quantify the extent to which advertising changes with the state of the economy, and develop empirical generalizations. In a third step, we examine the cross-country variation in advertising's cyclical dependence, and test our hypotheses on the role of cultural factors in shaping these differences, while controlling for economic factors.

\section{Extracting the Business-Cycle Component}

We use the well-known $\underline{H}$ odrick and Prescott (1997) filter to extract the business-cycle component from each advertising and economic-activity series. The HP filter decomposes a time series in (i) a gradually-evolving trend component, and (ii) cyclical fluctuations around it. To obtain the cyclical component in advertising spending $\left(A D V_{t}^{c}\right)$, one first models the trend $\left(A D V_{t}^{\text {trend }}\right)$, which is subsequently removed from the observed series, $\left(A D V_{t}\right)$ :

$$
A D V_{t}^{c}=A D V_{t}-A D V_{t}^{\text {trend }}
$$

with $A D V_{t}$ the log-transformed advertising series at time $t$. The log-transformation ensures that the units of $A D V_{t}^{c}$, when multiplied by 100 , represent percentage deviations from the series' growth path (Stock and Watson 1999). This facilitates the comparison across series. $A D V_{t}^{\text {trend }}$ in Equation (1) is obtained by minimizing (Holly and Stannett 1995):

(2) $\sum_{t=1}^{T}\left(A D V_{t}-A D V_{t}^{\text {trend }}\right)^{2}+\lambda \sum_{t=2}^{T-1}\left(\left(A D V_{t+1}^{\text {trend }}-A D V_{t}^{\text {trend }}\right)-\left(A D V_{t}^{\text {trend }}-A D V_{t-1}^{\text {trend }}\right)\right)^{2}$

The first quadratic term in (2) provides a measure of "goodness of fit", while the second quadratic term determines the smoothness of the derived trend. The solution to (2) implies a trade-off between fit and smoothness, as determined by the parameter $\lambda$. The larger the value of $\lambda$, the smoother the trend series becomes (Hodrick and Prescott 1997). As extreme cases, one obtains a linear trend $(\lambda=\infty)$ or a perfect, piece-meal (linear spline) interpolation $(\lambda=0)$ (Speight and McMillan 1998). Current empirical practice is to set $\lambda=10$ for annual data (Baxter and King 1999). We follow this practice, but will test the robustness of our key findings to this choice. 
Even though the HP-filter has been used frequently in prior research, it cannot easily accommodate sudden interventions or structural breaks in the series. Their effect tends to be smoothed along with the traditional HP-trend, and is therefore spread forward and backward (Funke 1998). As such, the standard HP-filter becomes less appropriate when a structural break is likely to be present in the series. This is particularly relevant in our setting, as the introduction of commercial television in several of the countries in our sample during the time period considered may have caused a level and/or trend shift in the series (Kornelis, Dekimpe, and Leeflang 2008). However, the HP-filter is a special case of a structural time-series model, whose state-space representation can easily be extended to account for potential structural breaks (Harvey and Jaeger 1993). The standard HP-trend is obtained from the following state-space formulation:

$$
\begin{aligned}
& A D V_{t}^{\text {trend }}=A D V_{t-1}^{\text {trend }}+\delta_{t-1}+\eta_{t} \\
& \delta_{t}=\delta_{t-1}+\zeta_{t}
\end{aligned}
$$

where $\delta_{t}$ represents the slope. The normal white-noise disturbances $\eta_{t}$ and $\zeta_{t}$ are independent of each other, with $\sigma_{\eta}^{2}$ and $\sigma_{\zeta}^{2}$ restricted to, respectively, 0 and 1/ (following Harvey and Jaeger 1993; Speight and McMillan 1998). To correct for a potential break in the underlying trend due to the introduction of commercial television, we augment (3a) and (3b) with intervention dummy variables (Harvey 2006). A pulse dummy $w_{t}$ (with $w_{t}=1$ if $t=$ intervention date, and 0 otherwise) is added to (3a) to allow for a shift in the level of the series, and to (3b) for a change in the growth rate or slope, resulting in:

$$
\begin{aligned}
& A D V_{t}^{\text {trend }}=A D V_{t-1}^{\text {trend }}+\delta_{t-1}+\lambda_{1} w_{t}+\eta_{t} \\
& \delta_{t}=\delta_{t-1}+\lambda_{2} w_{t}+\zeta_{t} .
\end{aligned}
$$

The trend component estimated from (4a) and (4b) is then subtracted from the observed series to arrive at the business-cycle component. A similar procedure is used to derive the cyclical component $G D P_{t}^{c}$ from the GDP-series. 


\section{Quantifying the Extent of Cyclical Sensitivity: The Co-Movement Elasticity}

To quantify the sensitivity of advertising spending to the state of the economy, we derive the cyclical co-movement, which measures the extent to which business-cycle fluctuations in the economy as a whole translate into cyclical fluctuations in advertising spending. In line with Deleersnyder et al. (2004) and Lamey et al. (2007), we regress the cyclical component of the advertising series $\left(A D V_{t}^{c}\right)$ on the cyclical component in real GDP:

$$
A D V_{t}^{c}=\beta G D P_{t}^{c}+\varepsilon_{t} \quad \text { with } t=1, \ldots, T .
$$

Since both $A D V_{t}^{c}$ and $G D P_{t}^{c}$ represent percentage deviations, $\beta$ can be interpreted as an elasticity. Both series are zero-reverting after filtering. Therefore it is not necessary to include an intercept in Equation (5). As the business-cycle filter may induce serial correlation in the data (Engle 1974), we allow for an autoregressive error term when needed (based on the BIC criterion).

The sign of the co-movement elasticity $\beta$ in Equation (5) indicates whether advertising moves in the same or opposite direction as the economic activity. Its magnitude reflects the extent to which fluctuations in the economy get attenuated or amplified in advertising expenditure.

\section{Explaining Cross-Country Differences}

In a final stage, we pool the estimated co-movement elasticities across all countries $(i)$ and media $(j)$, and regress them on the proposed cultural variables: long-term orientation $\left(L T O_{i}\right)$, power distance $\left(P D I_{i}\right)$, uncertainty avoidance $\left(U A I_{i}\right)$, and collectivism $\left(C O L_{i}\right)$. We control for a country's economic context through the following variables: the importance of the stock market $\left(S T O C K M_{i}\right)$, the importance of foreign-owned multinational subsidiaries $\left(F O S_{i}\right)$ and real per capita income $\left(I N C O M E_{i}\right)$. To account for possible differences across media, three dummy variables $M D_{j}^{m}$ are included (with $M D_{j}^{m}=1$ if $j=m ; m=1,2,3$ for, respectively, magazines, newspapers, and radio, with television as reference group). To control for unobserved differences between geographical regions, we include five continent-dummy variables $C D_{i}^{k}$ with $C D_{i}^{k}=1$ if country $i$ belongs to continent $k$ 
$(k=1, \ldots, 5)$, for distinguishing between countries across each continent in our sample, North America being the reference continent. While these covariates are not the focus of our study, controlling for their effects provides a stronger test of our substantive hypotheses. This results in the following regression specification:

(6) $\hat{\beta}_{i j}=a+\left[\begin{array}{lllllll}b_{1} & b_{2} & b_{3} & b_{4} & b_{5} & b_{6} & b_{7}\end{array}\right] .\left[\begin{array}{c}\operatorname{LTO}_{i} \\ \operatorname{PDI}_{i} \\ U A I_{i} \\ \operatorname{COL}_{i} \\ \operatorname{STOCKM}_{i} \\ \operatorname{FOS}_{i} \\ \operatorname{INCOME}_{i}\end{array}\right]+\sum_{m=1}^{3} c_{m} \cdot M D_{j}^{m}+\sum_{k=1}^{5} d_{k} \cdot C D_{i}^{k}+\mu_{i j}$.

We account for the non-independence between observations from the same country by estimating Equation (6) using GLS. ${ }^{3}$ Our dependent variable - but not our independent variables - is an estimated quantity. As such, it may be characterized by differing degrees of estimation accuracy. The estimates of the standard errors may be biased if the residuals exhibit heteroskedasticity. We conducted the White test, and found that heteroskedasticity was not an issue $(p>.10)$.

\section{DATA}

Annual advertising data are obtained through the World Advertising Research Center (WARC) and ZenithOptimedia. The data cover over two decades of advertising spending in 37 countries. They are obtained through surveys with national agencies, and encompass all paid-for regional and national advertising. The sample includes 16 European countries (Austria, Belgium, Denmark, Finland, France, Germany, Greece, Ireland, Italy, the Netherlands, Norway, Portugal, Spain, Sweden, Switzerland, U.K.), 3 North-American countries (Canada, Costa Rica, U.S.), 3

\footnotetext{
${ }^{3}$ It is clear that the errors may, to some extent, be dependent on each other. For example, we expect $\operatorname{Cov}\left(\mu_{i 1}, \mu_{i 2}\right) \neq 0$ if both $\mu_{i 1}$ and $\mu_{i 2}$ are related to media from the same country $i$. We account for the non-independence between observations from the same country by modeling the error term as: $\mu_{i j}=r_{i}+\delta_{i j}$, with $r_{i} \sim \operatorname{IID}\left(0, \sigma_{r}^{2}\right)$, the countryspecific component, and $\delta_{i j} \sim \operatorname{IID}\left(0, \sigma_{\delta}^{2}\right)$, the random error component. The resulting model allows for a Generalized Least Squares estimation, which we implement following the two-step procedure used in Lemmens et al. (2007).
} 
South American countries (Argentina, Brazil, and Chile), 12 Asian countries (Hong Kong, India, Japan, Kuwait, Philippines, Saudi Arabia, Singapore, South Korea, Taiwan, Thailand, Turkey, United Arab Emirates), 2 countries from Oceania (Australia, New Zealand), and South Africa on the African continent. Collectively, these countries account for $84 \%$ of the worldwide ad spending (2004 figures). The data contain spending information on four key media: magazines, newspapers, radio and television, as well as the total advertising spending (including also smaller media as outdoor and Internet spending) in the country.

For 85 country-media combinations, 25 years of data (i.e., 1980-2004) are available, which is considerably longer than in most previous studies on aggregate advertising spending (e.g., Ashley, Granger, and Schmalensee 1980; Didow and Franke 1984). For 33 combinations, we have data for at least 17 years, a time period still sufficiently long to capture multiple economic cycles (Deleersnyder et al. 2004). For the remaining country-media combinations, no data are available or a particular medium is hardly used in a country (operationalized as a share in national advertising in Table 1 below 5\%). Thus, we have 118 country-media combinations for further analysis.

To assess the cyclical sensitivity of the economy as a whole, we use the respective countries' GDP (Source: United Nations' Statistics Division). Fluctuations in aggregate output have been found to be at the core of the business cycle (Stock and Watson 1999). We inflation-adjust both the advertising and GDP series, using each country's Consumer Price Index (Source: United Nations' Statistics Division). Co-movement elasticities are calculated per country, using advertising and GDP data in local currencies. This minimizes issues related to varying exchange rates.

Information on the cultural characteristics is obtained from Hofstede $(2001,2004) .{ }^{4}$ The importance of the stock market is measured as the ratio of the stock market capitalization to

\footnotetext{
${ }^{4}$ For five countries, information on Long-Term Orientation was missing. To derive estimates for the missing observations, we used the 'Expected Maximization Maximum Likelihood' imputation technique advocated by Schafer and Graham (2002), which we applied to the complete country list published in Hofstede (2001). Omitting countries with missing LTO values did not affect any of our substantive conclusions.
} 
national GDP, averaged over the two available data points 1990 and 1998 (source: World Development Report 1999/2000 at www.worldbank.org). The relative importance of foreign-owned multinational subsidiaries in each country is obtained from Carlin, Charlton, and Mayer (2007). The data express the percentage of all listed firms in a country that are foreign-owned subsidiaries. Foreign-owned subsidiaries are defined as all firms that have a parent in another country which owns more than $50 \%$ of the subsidiary's equity. Real per capita income (in thousands of US dollars) is averaged over the period 1980-2004 (Source: US Department of Agriculture).

Information is also collected on the introduction date of commercial television in each country. For 21 countries, the introduction date fell within our sample period. In the remaining countries, commercial television was introduced before the time span studied. The main sources used to identify these break points are: the Museum of Broadcast Communications Encyclopedia of Television (Newcomb 2004), the website of the European Journalism Centre (www.ejc.nl), and a variety of websites of commercial television stations and national broadcasting institutions.

\section{RESULTS}

First, we discuss some descriptive findings on advertising spending in the different countries, based on their 2004 figures. This sets the stage for our main findings concerning the extent of the cyclical sensitivity of their advertising, and the moderating role of the cultural environment.

\section{Overall Descriptive Statistics}

There is considerable variability between the countries, both in terms of the total amount of advertising, and in the percentage of their GDP spent on advertising (Table 1). The smallest absolute advertising spender in our sample (based on 2004 figures) is Costa Rica (slightly less than one quarter of a billion dollars), while the biggest absolute spender is the U.S., with over \$145 billion. These differences can be attributed in part to differences in the size of the countries' economy. However, we also observe considerable variability in the percentages of their GDP that is spent on advertising, ranging from a low of .31\% in Saudi Arabia to a high of $3.07 \%$ in Hong 
Kong. Considerable differences are also observed between various large, developed, economies, most notably between the U.S. (1.24\%) and Germany (.75\%), Italy (.64\%), France (.60\%), and Japan (.76\%). On the other hand, advertising pressure in the U.S. is almost similar to the U.K. (1.17\%), i.e., the other country frequently studied in previous research. These differences in relative and absolute advertising pressure suggest considerable cross-national differences in the advertising environment. This further underlines the importance of moving beyond the U.S. and the U.K. in studying advertising's sensitivity to the business cycle.

Across all 37 countries, the largest proportion of advertising is typically spent on newspapers and television, followed by magazines, with radio accounting for the smallest part of total ad spending. However, also along this dimension, considerable variation is observed. For instance, in 17 countries, television advertising rather than newspaper advertising is most popular, while radio advertising turned out more important than advertising in magazines in 10 countries.

--- Insert Table 1 about here ---

\section{The Extent of Cyclical Sensitivity}

Co-movement elasticities are estimated using Equations (1) - (5). Figure 1 gives the distribution of the estimated 118 elasticities, both overall and per medium. The direction of the estimate (positive versus negative) informs on whether advertising's movements in relation to the economy are pro-cyclical or counter-cyclical. The magnitude of the estimate reveals whether fluctuations in advertising expenditure are inelastic $(<|1|)$ or elastic $(>|1|)$ with respect to changes in the general economic conditions. The majority of country-medium co-movement elasticities are pro-cyclical -- 88\% (104 out of 118) of the co-movement elasticities being positive. This confirms earlier anecdotal observations (Dobbs et al. 2002). Also, even though advertising strategists have long suggested that anti-cyclical advertising yields important benefits (see e.g., Frankenberger and Graham 2003 for a recent review), many companies do not heed this advice. More interestingly, a clear majority (62\%) of the co-movement elasticities is greater than one, and the average co- 
movement elasticity also exceeds one (meta-analytic $\mathrm{Z}=6.88 ; p<.01$ ). This documents that aggregated across a large set of countries on all continents, advertising is elastic with respect to business-cycle fluctuations. Thus, general business-cycle swings get amplified in advertising expenditure. The average (median) value is 1.39 (1.40), implying that every percentage deviation from GDP's long-term growth translates into a corresponding deviation of $1.4 \%$ in the advertising series. This result is driven by three media. Advertising expenditures on magazines (mean comovement elasticity $=1.70, \mathrm{Z}=5.72 ; p<.01)$, newspapers (mean $=1.54, \mathrm{Z}=6.52 ; p<.01)$, and television $($ mean $=1.27, \mathrm{Z}=1.68 ; p<.05)$ are elastic. ${ }^{5}$ Only advertising expenditures on the smallest medium, radio, have a co-movement elasticity not significantly greater than one. Table 2 summarizes the meta-analytic results.

Of particular interest are the co-movement elasticities in the U.S. After all, it is the largest advertising market by far. The average co-movement elasticity across all media in the U.S. is 1.91, while the elasticities for the individual media are 2.07 (magazines), 2.32 (newspapers), 1.69 (radio), and 1.57 (television). Thus, compared to the total sample, U.S. advertisers are more responsive to business cycle ups and downs.

--- Insert Table 2 and Figure 1 about here ---

\section{Explaining the Cross-Country Variability in Cyclical Sensitivity}

The distribution of the elasticities in Figure 1 reveals considerable cross-national differences in co-movement elasticities. Equation (6) is estimated to test our hypotheses concerning the role of national culture in the cross-national variation in advertising's sensitivity to the business cycle. The largest correlation between the different country-level predictors is .60, while the largest Variance Inflation Factor was 4.58. Hence, multicollinearity is not a major issue.

\footnotetext{
${ }^{5}$ Significance values refer to the null hypothesis that the co-movement elasticity equals one versus the alternative hypothesis that the co-movement elasticity exceeds one.
} 
Table 3 gives the GLS estimates. Coefficients are unstandardized regression coefficients. We also report Cohen's $\mathrm{d}$, one of the most frequently used effect-size metrics, where $.2, .5$, and .8 are indicative of a small, medium, and large effect, respectively (Cohen 1988).

H1 posits that advertising is less sensitive to business-cycle fluctuations in long-term oriented cultures. This hypothesis is supported: $b_{1}=-.02(p<.05)$. In line with $\mathrm{H} 2$, advertising expenditure is less sensitive to business-cycle fluctuations in countries high on power distance $\left(b_{2}=-.02 ; p<.05\right)$. We also find support for our expectation (H3) that advertising expenditure is more elastic in countries high on uncertainty avoidance: $b_{3}=.02(p<.01)$. However, there is no effect of cultural collectivism on advertising's co-movement elasticity $\left(b_{4}=-.01 ; p>.10\right)$. Thus, no support is found for H4. The effect-size estimates reveal a medium-small effect for long-term orientation, a medium effect for power distance, and a medium effect for uncertainty avoidance.

The effects of the control variables are also reported in Table 3. We find that in countries where the stock market plays a larger role in economic life, advertising reacts more strongly to business-cycle fluctuations than in countries where the role of the stock market is less prominent $\left(b_{5}=.82 ; p<.05\right)$. Further, in countries where more foreign multinationals are operative, advertising is less dependent on national (local) economic conditions $\left(b_{6}=-.08 ; p<.05\right) .{ }^{6}$ The effect of real income per capita is not significant.

We note a different cyclical dependence across the four media. Magazine spending $\left(c_{1}=.43 ; p\right.$ $<.05$ ) is more affected by economic fluctuations than television spending (which serves as baseline category). Also newspaper advertising has a higher cyclical dependence than television, even though the parameter fails to reach statistical significance $\left(c_{2}=.25 ; p>.10\right)$. Radio spending, in contrast, is less cyclically sensitive than television $\left(c_{3}=-.45, p<.05\right)$. Blank (1962) and Picard

\footnotetext{
${ }^{6}$ We examined whether the influence of national culture on advertising's co-movement elasticity is smaller in countries with more foreign-owned multinational subsidiaries. Specifically, we added to Equation (6) interaction terms between the percentage of foreign-owned subsidiaries and the cultural dimensions. These interaction terms were not significant $(p>.10)$, neither individually nor simultaneously.
} 
(2001) also found that print advertising is more cyclically sensitive than television and radio advertising. This result could be attributed to institutional differences such as a greater contractual flexibility for print advertising (Silk et al. 1999), and to the synergistic interaction between advertising and circulation revenues in print media (Abbring and Van Ours 1994). Finally, after controlling for the aforementioned factors, advertising in Asia, Europe, and South America is more elastic with respect to the state of the economy than North America, Oceania, and Africa.

--- Insert Table 3 about here ---

\section{Robustness checks}

We assess the robustness of our findings in several ways. First, given that business-cycle filters approximate the true business cycle, we evaluate the sensitivity of our findings, using a wide range of alternative $\lambda$ values, varying between $50 \%$ and $500 \%$ of its original value of $\lambda=10$. The results remain essentially unchanged. Second, we test endogenously for the presence of an additional break point in the derivation of the long-run and cyclical components. No additional breaks are

found. Third, we assess the stability of the co-movement estimates over the considered 25 year time span in 3 alternative ways, but find them to be stable over the time period considered. Fourth, we examine whether the emergence of Internet advertising from the late 1990s onward affects our conclusions, which is not the case. Finally, we consider whether our results could be a statistical artifact (i.c., correlation by construction), as the advertising industry is one of the sectors that make up a country's GDP. This is not the case. The same substantive insights are again obtained. Details on the various analyses and results are reported in the Web Appendix.

\section{CONSEQUENCES OF ADVERTISING SENSITIVITY TO THE BUSINESS CYCLE}

Our conceptualization and results suggest that myopic management - short-term, riskconscious, and herding behavior - results in a stronger response of advertising to business cycles. Although these results are of interest in their own right - after all, we are considering one of the main instruments of firms' marketing strategy - the question remains whether one should be 
concerned about this practice. Put differently, are there significant long-run social or managerial losses when companies tie ad spending too tightly to business cycles? We examine this issue by studying the effect of advertising's co-movement elasticity on the long-run growth of (i) the advertising industry, (ii) private-label share, and (iii) companies' stock price. The advertising industry is a major industry and contributor to the national economy in its own right, as well as an important employer of marketing people. ${ }^{7}$ Hence, a negative effect of a country's advertising comovement on the growth of its advertising industry constitutes a social loss. If pro-cyclical behavior contributes to private label growth, this constitutes a managerial loss for branded goods companies. Managerial losses are also incurred if pro-cyclical behavior leads to reduced stock-price performance for companies engaged in such behavior. Table 4 summarizes the results. Since the predictors in these models are estimated parameters, significance testing in all subsequent analyses is based on robust standard errors derived through the bootstrap method discussed in Nijs, Srinivasan, and Pauwels (2007).

--- Insert Table 4 about here ---

\section{Long-Run Growth of the Advertising Industry}

Background. We submit that in countries where advertising demand is strongly pro-cyclical, the advertising industry develops at a slower pace compared to countries where this co-movement is more modest. When the economy enters a downturn, dramatic reductions in the demand for advertising in highly pro-cyclical countries will result in a substantial number of layoffs and failures in the advertising industry (Picard and Rimmer 1999), which may not be easily recovered in a subsequent expansion. This conjecture is consistent with studies showing that it is difficult in good economic times to make up for losses in bad economic times (e.g., technology, [Döpke 2004, Fatás 2000], national-brand share [Lamey et al. 2007]). On the other hand, when advertising is

\footnotetext{
${ }^{7}$ In the U.S. alone, the advertising and public relations services industry employs over half a million people (2006 figures, source: U.S. Department of Labor; Bureau of Labor Statistics).
} 
maintained during contractions, we expect advertising know-how and new developments to be transferred more smoothly over time, resulting in higher long-term industry growth.

Method and results. We quantify long-run growth of the advertising industry as the average yearly growth rate in national advertising that remains after removing (using Equations (1)-(4)) the cyclical ups and downs. ${ }^{8}$ This is done for each of the 37 countries in our sample. These long-run industry growth rates are then regressed on the country's national advertising co-movement elasticity, while controlling for the long-run growth in its real GDP (estimated using the same procedure). The national-advertising co-movement elasticity is derived for each country based on the aggregate advertising expenses across all media. This allows us to also include smaller (e.g., outdoor) and more recent (e.g., Internet) media in the analysis. ${ }^{9}$

We find evidence that in countries where ad spending is more pro-cyclical, long-run growth in advertising is indeed lower $(b=-1.09, p<.05)$, for a large effect size (Cohen's $d=.72)$. In a country with a co-movement elasticity of 2.5 - i.e., a country which responds strongly pro-cyclically to business cycles (Figure 1), one can expect the yearly growth rate of the advertising industry to be 1.6 percentage points less than in a country where advertising fluctuations follow the business cycle (co-movement elasticity $=1$ ). Given that the average long-run industry growth across all 37 countries is about $6 \%$ per year, this is indeed a strong effect. These results show that stronger procyclical advertising adjustments are associated with significant, long-lasting economic and social losses for an important industry in the national economy.

\section{Long-Run Growth in Private-Label Share}

Background. Private labels have emerged as a fierce competitor to national brands in a variety of industries, but most notably packaged goods. Heavy advertising by national-brand manufacturers

\footnotetext{
${ }^{8}$ The first difference of a log-transformed series is a good measure for the growth rate of the original series (Franses and Koop 1998). However, rather than deriving the average growth rate of the advertising series itself, we derive the average growth rate in the long-run trend (as per Equations (1)-(4)) underlying that series.

${ }^{9}$ Similar conclusions are obtained when working with the combined spending across the four focal media (magazines, newspapers, television and radio).
} 
is arguably one of the most effective weapons against private-label growth (Kumar and Steenkamp 2007). Pro-cyclical advertising strategies imply that brands are supported less when they need it most, namely in bad economic times. Lamey et al. (2007) speculate that cyclical reductions in advertising support contribute to the long-run erosion of the market share of national brands, as part of the customers lost to private labels during a recession will not switch back to national brands when the economy recovers. Hence, we expect stronger long-run growth in private-label share when the advertising co-movement elasticity is higher.

Method and results. We examine the growth in private-label share over the 25-year period considered in this paper (1980-2004). For 30 countries in our sample, we were able to secure information on their private-label share for both 1980 and 2004, using various sources (e.g., ACNielsen, GfK). Long-run growth in private-label share is proxied by the difference in privatelabel share between 2004 and $1980 .{ }^{10}$ Our data pertain to packaged goods, as this is the only industry where such information is systematically collected in different countries. Long-run private-label growth is regressed on the countries' national advertising co-movement elasticity (see above), and (as before) we include each country's long-run economic growth as a control variable.

We find initial evidence that long-run growth in private-label share is higher in countries with higher co-movement elasticity, given a marginally significant positive parameter estimate $b=2.84$ corresponding to a (two-sided) $p$-value of .106 , for a medium-large effect (Cohen's $d=.64$ ). In a country with a co-movement elasticity of 2.5 , one can expect that over a period of 25 years private label share grows 4.3 percentage points, or about .2 percentage points annually, more than a country where advertising fluctuations follow the business cycle (co-movement elasticity $=1)$. These results materialize in the long run, but given the size of the packaged-goods industry, the

\footnotetext{
${ }^{10}$ As no time-series was available on the private-label shares, we could not implement the aforementioned method used to derive the long-run growth in the advertising industry. Also, note that the private-label share series deals with all CPG categories, while the advertising co-movement elasticity covers the advertising spending across both CPG and non-CPG categories. It was not possible to obtain separate CPG advertising spending across all 30 countries. For the US, however, we were able to obtain this information from TNS. The correlation between the two advertising spending series (i.e., total advertising across 124 CPG categories, and total advertising spending used in our analyses) was .97.
} 
shift in sales from national brands to private labels amounts to billions of dollars for economies of reasonable size. Hence, our results suggest that larger national advertising co-movement opens the door for private-label growth in periods when national brands are vulnerable, and offer empirical support that some of the cyclical cuts in advertising have a permanent adverse effect.

\section{Long-Run Growth in Firm Performance}

Background. Advertising executives have repeatedly claimed that counter-cyclical, or at least inelastic, advertising may be more effective than pro-cyclical, elastic advertising (O'Toole 1991). The argument is that companies get more bang for the buck in difficult economic times. Moreover, it can be argued that company performance benefits from a consistent long-term view on the management of its strategic assets (Srivastava et al. 1998). We examine whether the degree to which an individual company ties its ad spending strongly to the business cycle has indeed a detrimental effect on its long-run performance. Whereas the previous two analyses used aggregate, country-level advertising data, we now employ information on the advertising co-movement elasticity for individual firms. We use the long-term evolution in the firm's share price as our metric of firm performance. This measure is forward looking and risk adjusted, and integrates multiple dimensions of performance (sales, profits, cash flow, earnings volatility), and is less easily manipulated by managers than other measures. Consequently, marketing academics have increasingly recognized share price evolution as an important metric for evaluating the effectiveness of marketing strategies (e.g., Feng et al. 2008; Gielens et al. 2008).

Method and results. Each year, Advertising Age publishes a list of the top 50 global advertisers, with the amount spent on advertising in the preceding year. Twenty-six of these firms were consistently listed in the period 1986-2006, and were publicly listed on the stock exchange (source: Datastream). For each of these 26 firms, stock-price information over the same data period was acquired. As the Advertising Age list deals with global advertisers, we used the global real GDP (source: World Bank World Development Indicators at www.ers.usda.gov) in Equations (2)- 
(5) to calculate the advertising co-movement elasticity for each firm. Likewise, we apply the HP filter to the firm's stock-price time series. The long-run growth in firm's stock price is the average yearly percentage growth in the trend underlying the stock-price evolution, obtained following the procedure described in footnote 8 . We subsequently regressed the firm's average long-run stock price growth on its global advertising co-movement elasticity.

We find that the more pro-cyclical a firm's advertising expenditure is, the worse its long-run stock price performance $(b=-.53, p<.10)$. The associated effect size of .78 indicates a large effect of the co-movement elasticity on firm performance. To illustrate, companies that do not tie their advertising spending to the business cycle (co-movement elasticity of 0 ) exhibit an average yearly percentage growth in their stock price that is $1.3 \%$ higher compared to firms that exhibit clear procyclical advertising behavior (co-movement elasticity $=2.5$ ). Given the market capitalization of these global companies, this represents billions of dollars of shareholder value. Our findings provide hard evidence for received wisdom among advertising executives that pro-cyclical advertising reduces company performance.

The (unweighted) average co-movement elasticity across these 26 global firms is 2.19 , which provides evidence that on average, global firms exhibit pro-cyclical advertising behavior. However, there are courageous companies that go against the prevailing trend. An example of a company that pursues such a strategy with great success is Reckitt-Benckiser, a leading U.K.-based global packaged goods company (Financial Times 2005). Despite difficult economic times at the onset of the $21^{\text {st }}$ century, it raised its real global ad budget in 2001 by $10 \%$, moving it from rank 38 to rank 30 on total worldwide ad spending. By comparison, total real advertising expenditure aggregated across the other companies in the top-50 of global advertisers decreased by 5\% (Advertising Age 2002). Its strategy has been rewarded by the financial markets. Its share price gained $8.5 \%$ in 2001 , and $20.5 \%$ in the post recession year 2002. By comparison, the London Stock Exchange benchmark FTSE 250 declined $10.7 \%$ in 2001 and $26.2 \%$ in 2002. 


\section{DISCUSSION}

In this paper, we examined the cyclical sensitivity of advertising over multiple decades, for 4 media, in 37 countries. We obtained the empirical generalization that on average, advertising is elastic with respect to business-cycle fluctuations, the average co-movement elasticity being 1.4. Hence, a $1 \%$ cyclical drop (expansion) in real GDP translates (on average) into a $1.4 \%$ cyclical reduction (increase) in real advertising spending. But there are differences across media. Print advertising is more sensitive to the business cycle than radio and television advertising.

Our results also reveal considerable cross-national differences in advertising's cyclical sensitivity. Prior studies found that culture matters in advertising communication, as social roles, use of language, and intrinsic consumer preferences embedded in a certain cultural context can affect consumers' appreciation and response to advertising messages (Douglas and Craig 2007). This study augments these findings by showing that the cultural context also affects managerial advertising decisions. Advertising expenditure behaves less cyclically in countries high on longterm orientation and power distance, while it behaves more cyclically in countries high on uncertainty avoidance. These findings are consistent with the two underlying meta-dimensions in our conceptualization, viz., firms' view on the role of advertising as a strategic investment as opposed to an expense, and the role of herding in advertising decision processes. Finally, we show that there are long-run social and managerial losses when advertising is tied too tightly to the business cycle. Growth of the advertising industry is impeded, private-label growth is stimulated, and firm performance suffers.

Our results are a step toward beginning to understand why and how companies' marketing behavior is systematically related to the cultural and economic context in which they operate. At a more abstract level, our research highlights the impact of general economic conditions and cultural and economic structures on managers' decisions with respect to one of their key competitive weapons. As such, our study adds to the rational, context-free perspective taken in micro-economic 
models of advertising expenditures (see e.g., Lipczynski and Wilson 2001, p. 188-218). It reminds us that even though both managers and researchers like to see advertising budgets as the outcome of a rational decision-making process (see e.g., Danaher and Rust 1994), this rationality rests, to a large extent, on what Hofstede (2001, p. 361) calls "prerational” cultural considerations.

\section{Managerial Implications}

Our findings suggest that most companies still perceive advertising as a short-term, elastic expense rather than as a strategic, inelastic long-term investment in the company's future and the equity of its brands. Our study provides initial evidence that excessive pro-cyclical advertising behavior results in significant long-term social and managerial losses. In combination, our findings lead us to propose several recommendations for advertisers and advertising agencies.

Provided the company has the financial resources, it is recommended to implement an advertising strategy that is inelastic - or even anti-cyclical - with respect to the business cycle. Such a strategy is associated with superior long-run firm performance. It also helps to reduce the growth of private labels. Our results also provide a benchmark for the amount of advertising needed to maintain firms' share-of-voice in different markets. Many firms aim to maintain their share-ofvoice (Danaher and Rust 1994), yet feel the urge to cut advertising in difficult times. Knowing the overall reduction to be expected in different countries can help to balance both objectives.

We observe considerable cross-media variability in co-movement elasticity. This offers risk diversification opportunities to ad agencies, which are advised to develop expertise in multiple media. International diversification to markets with lower cyclical sensitivity offers a further opportunity to reduce their business risk. Our results can be helpful in selecting those markets. Also, since the co-movement elasticities are systematically related to cultural and economic drivers, ad agencies can use this information when considering countries not yet in our sample. 


\section{Limitations and Future Research}

Our results show that the advertising sector is more sensitive to the business cycle than the economy as a whole. However, within a given country, some industries may reduce their advertising more than others. Future research should investigate the extent and drivers of crossindustry differences in advertising sensitivity. Is cyclical sensitivity more pronounced in concentrated industries, is it stronger in impulse-categories, do advertisers of durable goods react differently to economic swings than advertisers of non-durables and/or services?

We develop our cultural hypotheses using two mechanisms, viz., managers' view on the role of advertising per se and the process through which the advertising budget is set, but we do not directly test this. Future research could attempt to investigate these mechanisms in detail. Moreover, while our cultural hypotheses are generally supported, we find no evidence that cultural collectivism affects advertising's co-movement elasticity. We speculate that herding in collectivistic societies could instigate managers to follow the dominant behavior observed outside the company, but that they may, at the same time, find it harder to implement large (unpopular) budget cuts in advertising, as they fear reprisal from other managers within their firm (Tan et al. 1998). Managers in collectivistic countries are clearly tied to group support for their decisions. Cutting down expenses is not a popular strategy, and is likely to provoke resistance from other managers at the firm. If advertising budgets are not cut in bad economic times, there may be less scope for large budget expansions when the economy improves. This internal group pressure may counteract the tendency to engage in herding behavior in collectivistic societies, which might explain the non-significant effect. Research is needed to examine whether this explanation is correct, and to further clarify the role of cultural collectivism in advertising decisions.

Alternatively, one could consider the role of other drivers in managers' decision on whether or not to follow the business cycle. Even though local advertisers typically account for a vast majority of all advertising in a country, exchange-rate considerations could play a role in the allocation 
decision of multinational firms. The impact of currency-related considerations on marketing decision making merits future research attention.

We limit the analysis to four key media, which puts some restrictions on the generalizability to new advertising media such as the Internet, for which time series of sufficient length are currently not available. Future research should assess whether or not online advertising is better able to resist severe economic downswings than the established media, since its effects are easier to measure, and hence to justify even in bad economic times (cf. The Economist 2008).

Although we have provided initial evidence on the implications of pro-cyclical advertising behavior, more research is clearly needed at other levels of entity aggregation. For example, it would be beneficial to link advertising cyclicality at the industry level to industry growth in general as well as to private-label growth in that industry. Research at the company level could be expanded to include smaller advertisers as well.

In sum, our paper shows that (i) the use of a key marketing instrument is systematically related to wider economic conditions, (ii) the way managers adjust this instrument over the business cycle is systematically related to the cultural context in which they live, and (iii) their cyclical reaction can have important social and managerial consequences. However, we do not want to suggest that advertising is the only marketing instrument sensitive to business cycles, or that its cyclicality is the sole, or even the most important, marketing factor influencing company success in the marketplace. We have only begun to scratch the surface. Hopefully, researchers will take our lead and make business cycles the substantive focus of some of their work. 


\section{REFERENCES}

Abbring, Jaap A. and Jan C. Van Ours (1994), “Selling News and Advertising Space: The Economics of Dutch Newspapers," De Economist, 142 (2), 151-170.

Abraham, Magid M. and Leonard M. Lodish (1993), “An Implemented System for Improving Promotion Productivity Using Store Scanner Data," Marketing Science, 12 (3), 248-269. Advertising Age (2002), Special Report: Global Marketers 2002. Chicago: Advertising Age. Ashley, Richard, Clive W.J. Granger, and Richard Schmalensee (1980), “Advertising and Aggregate Consumption: An Analysis of Causality," Econometrica, 48 (5), 1149-1167. Barwise, T. Patrick (1999), Advertising in a Recession: The Benefits of Investing for the Long Term. Henley-on-Thames, UK, NTC Publications Ltd.

Baxter, Marianne (1994), "Real Exchange Rates and Real Interest Differentials: Have We Missed the Business-Cycle Relationship?" Journal of Monetary Economics, 33 (1), 5-37. and Robert G. King (1999), “Measuring Business Cycles: Approximate Band-Pass Filters

for Economic Time Series,” Review of Economics and Statistics, 81 (4), 575-593.

Bikhchandani, Sushil, David Hirshleifer, and Ivo Welch (1992), “A Theory of Fads, Fashion, Custom and Cultural Change as Information Cascades," Journal of Political Economy, 100 (5), 992-1026.

Blank, David M. (1962), “Cyclical Behavior of National Advertising,” Journal of Business, 35 (January), 14-27.

Bronnenberg, Bart J., Carl F. Mela, and William Boulding (2006), "The Periodicity of Pricing," Journal of Marketing Research, 43 (August), 477-493.

Carlin, Wendy, Andrew Charlton, and Colin Mayer (2007), "Multinational Ownership and Subsidiary Investment," working paper, CEPR. Available at: http://ssrn.com/abstract=958505. Chowdhury, Abdur R. (1994), “Advertising Expenditures and the Macro-Economy: Some New Evidence," International Journal of Advertising, 13 (1), 1-14. 
Christiano, Lawrence J. and Terry J. Fitzgerald (1998), “The Business Cycle: It’s Still a Puzzle,” Economic Perspectives, 22 (4), 56-83.

Cohen, Jacob (1988), Statistical Power Analysis for the Behavioral Sciences, Hillsdale, NJ: Erlbaum, $2^{\text {nd }}$ ed.

Danaher, Peter J. and Roland T. Rust (1994), "Determining the Optimal Level of Media Spending," Journal of Advertising Research, 34 (January-February), 28-34.

Deleersnyder, Barbara, Marnik G. Dekimpe, Miklos Sarvary, and Philip M. Parker (2004), "Weathering Tight Economic Times: The Sales Evolution of Consumer Durables over the Business Cycle," Quantitative Marketing and Economics, 2 (4), 347-383.

Didow, Nicholas M., Jr. and George R. Franke (1984), "Measurement Issues in Time-Series Research: Reliability and Validity Assessment in Modeling the Macroeconomic Effects of Advertising,” Journal of Marketing Research, 21 (February), 12-19.

Dobbs, Richard F., Tomas Karakolev, and Francis Malige (2002), "Learning to Love Recessions," The McKinsey Quarterly, Special Edition Issue 2, 6-9.

Döpke, Jörg (2004), “The Effect of Business Cycles on Growth - Time Series Evidence for the G7 Countries Using Survey-based Measures of the Business Cycle," CESifo Economic Studies, 50 (2), 333-349.

Douglas, Susan P. and Samuel C. Craig (2007), "Advertising Across Cultures," in The Sage Handbook of Advertising, Gerard J. Tellis and Tim Ambler, eds. London: Sage Publications Ltd., 416-429.

Engle, Robert F. (1974), “Band Spectrum Regression,” International Economic Review, 15 (1), 111.

Fatás, Antonio (2000), “Endogenous Growth and Stochastic Trends," Journal of Monetary Economics, 45 (1), 107-128. 
Feng, Eric, Robert W. Palmatier, and Jan-Benedict E.M. Steenkamp (2008), "Effect of Service Transition Strategies on Firm Value," Journal of Marketing, 72 (September), 1-14.

Ferguson, George A. (1981), Statistical Analysis in Psychology and Education, New York, NY: McGraw-Hill, $5^{\text {th }}$ ed.

Financial Times (2005), “'Craziness’ Makes Merger Work for Reckitt Benckiser,” (February 9), 21. (2008), "Cuts in UK Advertising to Be 'Sharpest' Since 9/11," (July 14), 3.

Frankenberger, Kristina D. and Roger C. Graham (2003), "Should Firms Increase Advertising Expenditures During Recessions?” MSI report no. 03-003, Cambridge, M.A.

Franses, Philip Hans and Gary Koop (1998), “On the Sensitivity of Unit-Root Inference to Nonlinear Data Transformations," Economics Letters, 59 (1), 7-15.

Funke, Michael (1998), “Measuring the German Output Gap Using Unobserved Component Models,” Discussion Paper no. 02-98, Hamburg University and London Business School. Gielens, Katrijn, Linda Van de Gucht, Jan-Benedict E.M. Steenkamp, and Marnik Dekimpe (2008), "Dancing with the Giant: The Effect of Wal-Mart's Entry in the U.K. on the Performance of European Retailers," Journal of Marketing Research, 45 (in press).

Harvey, Andrew C. (2006), "Forecasting with Unobserved Components Time Series Models," in Handbook of Economic Forecasting, Vol. 1, Graham Elliot, Clive W.J. Granger, and Allan Timmermann, eds. New York: Elsevier North-Holland, 327-412. and Albert Jaeger (1993), "Detrending, Stylized Facts and the Business Cycle," Journal of Applied Econometrics, 8 (3), 231-247.

Hess, Gregory D. and Kwanho Shin (1997), "International and Intranational Business Cycles," Oxford Review of Economic Policy, 13 (3), 93-109.

Hodrick, Robert J. and Edward C. Prescott (1997), "Postwar U.S. Business Cycles: An Empirical Investigation," Journal of Money, Credit, and Banking, 29 (1), 1-16. 
Hofstede, Geert (1994), "Management Scientists Are Human," Management Science, 40 (January), 4-13.

(2001), Culture's Consequences: Comparing Values, Behaviors, Institutions, and Organizations across Nations, Thousand Oaks, CA: Sage Publications.

Holly, Sean and Mike Stannett (1995), “Are There Asymmetries in UK Consumption? A Time Series Analysis," Applied Economics, 27 (8), 767-772.

Jacobson, Robert and David Aaker (1993), "Myopic Management Behavior With Efficient, But Imperfect, Financial Markets,” Journal of Accounting and Economics, 16 (4), 383-405.

Jensen, Michael C. and William H. Meckling (1976), “Theory of the Firm: Managerial Behavior, Agency Costs, and Ownership Structure," Journal of Financial Economics, 3 (4), 305-360.

Jung, Chulho and Barry J. Seldon (1995), “The Degree of Competition in the Advertising Industry," Review of Industrial Organization, 10 (1), 41-52.

Kornelis, Marcel, Marnik G. Dekimpe, and Peter S.H. Leeflang (2008), “Does Competitive Entry Structurally Change key Marketing Metrics?" International Journal of Research in Marketing (forthcoming).

Kumar, Nirmalya and Jan-Benedict E.M. Steenkamp (2007), Private Label Strategy: How to Meet the Store Brand Challenge, Boston, MA: Harvard Business School Press.

Lamey, Lien, Barbara Deleersnyder, Marnik G. Dekimpe, and Jan-Benedict E.M. Steenkamp (2007), "How Business Cycles Contribute to Private-Label Success: Evidence from the U.S. and Europe," Journal of Marketing, 71 (January), 1-15.

Lemmens, Aurelie, Christophe Croux, and Marnik G. Dekimpe (2007), "Consumer Confidence in Europe: United in Diversity,” International Journal of Research in Marketing, 24 (2), 113-127. Lipczynski, John and John Wilson (2001), Industrial Organization: An Analysis of Competitive Markets, Reading, MA: Pearson. 
Low, George S. and Jakki J. Mohr (1999), "Setting Advertising and Promotion Budgets in MultiBrand Companies," Journal of Advertising Research, 39 (January-February), 67-78.

Mela, Carl F., Kamel Jedidi, and Douglas Bowman (1998), “The Long-Term Impact of Promotions on Consumer Stockpiling Behavior,” Journal of Marketing Research, 35 (May), 250-262.

Mizik, Nathalie and Robert Jacobson (2007), "Myopic Marketing Management: Evidence of the Phenomenon and Its Long-Term Performance Consequences in the SEO Context," Marketing Science, 26 (3), 361-379.

Newcomb, Horace (2004), The Museum of Broadcast Communications Encyclopedia of Television. New York: Fitzroy Dearborn.

Nijs, Vincent, Shuba Srinivasan, and Koen Pauwels (2007), "Retail Price Drivers and Retail Profits," Marketing Science, 26 (4), 473-487.

O’Toole, John (1991), “Advertising in a Recession: The Best Defense Is a Good Offense,” paper presented at the third Annual ARF Advertising and Promotion Workshop, New York, NY: Advertising Research Foundation.

Picard, Robert G. (2001), "Effects of Recessions on Advertising Expenditures: An Exploratory Study of Economic Downturns in Nine Developed Nations," The Journal of Media Economics, $14(1), 1-14$.

and Tony Rimmer (1999), "Weathering a Recession: Effects of Size and Diversification on Newspaper Companies," The Journal of Media Economics, 12 (1), 1-18.

Quarles, Rebecca C. and Leo W. Jeffres (1983), “Advertising and National Consumption: A Path Analytic Re-Examination of the Galbraithian Argument," Journal of Advertising, 12 (2), 4-33. Roark, Virginia and Gerald C. Stone (1994), “Do Managers Forecast the Newspaper Industry’s Economy?" The Journal of Media Economics, 7 (2), 29-38.

Rosenthal, Robert (1991), Meta-Analytic Procedures for Social Research. Newbury Park: Sage Publications. 
Roth, Martin S. (1995), "The Effects of Culture and Socioeconomics on the Performance of Global Brand Image Strategies,” Journal of Marketing Research, 32 (May), 163-175.

Saunders, John, Philip Stern, Robin Wensley, and Ros Forrester (2000), "In Search of the Lemmus Lemmus: An Investigation into Convergent Competition,” British Journal of Management, 11 (Special Issue), S81-S95.

Schafer, Joseph L. and John W. Graham (2002), "Missing Data: Our View of the State of the Art," Psychological Methods, 7 (2), 147-177.

Schneider, Susan C. and Jean-Louis Barsoux (2002), Managing Across Cultures, London: FT Prentice Hall, $2^{\text {nd }}$ ed.

Silk, Alvin J., Lisa R. Klein, and Ernst R. Berndt (1999), "Restructuring in the U.S. Advertising Media Industry,” working paper no. 99-126, Harvard Business School, Harvard University. Smith, Peter B. and Shalom H. Schwartz (1997), "Values," in Handbook of Cross-Cultural Psychology, Volume 3: Social Behavior and Applications, eds.: John W. Berry, Marshall H. Segall, and Cigdem Kagitcibasi, Boston, MA: Allyn and Bacon, 2nd edition, 77-118. Speight, Alan E.H. and David G. McMillan (1998), “Testing for Asymmetries in UK Macroeconomic Time Series,” Scottish Journal of Political Economy, 45 (2), 158-170. Srinivasan, Raji, Arvind Rangaswamy, and Gary L. Lilien (2005), “Turning Adversity into Advantage: Does Proactive Marketing during a Recession Pay off?” International Journal of Research in Marketing, 22 (2), 109-125.

Srivastava, Rajendra K., Tasadduq A. Shervani, and Liam Fahey (1998), "Market-Based Assets and Shareholder Value: A Framework for Analysis," Journal of Marketing, 62 (January), 2-18. Steenkamp, Jan-Benedict E.M., Vincent R. Nijs, Dominique M. Hanssens, and Marnik G. Dekimpe (2005), "Competitive Reactions and Advertising and Promotion Attacks," Marketing Science, 24 (1), 35-54. 
Stock, James H. and Mark W. Watson (1999), "Business-Cycle Fluctuations in US Macroeconomic Time Series," in Handbook of Macroeconomics, Vol. 1A, John B. Taylor, and Michael Woodford, eds. Amsterdam: Elsevier Science, 3-64.

Surowiecki, James (2004), The Wisdom of Crowds, New York: Doubleday.

Tan, Bernard C.J., Kwok Kee Wei, Richard T. Watson, Danial L. Clapper, and Erhraim R. McLean (1998), "Computer-Mediated Communication and Majority Influence: Assessing the Impact in an Individualistic and a Collectivistic Culture," Management Science, 44 (9), 1263-1278.

The Economist (2008), “The Advertising Market: Hard Sell,” January 26, 61-62.

Turner, Paul (2000), "Aggregate Advertising, Sales Volume and Relative Prices in the Long Run," Applied Economics Letters, 7 (8), 505-508.

White, John B. and Morgan P. Miles (1996), "The Financial Implications of Advertising as an Investment," Journal of Advertising Research, 36 (July/August), 43-52.

WARC (World Advertising Research Center) (2005), World Advertising Trends 2005. Oxfordshire: World Advertising Research Center. 
Table 1: Descriptive advertising statistics for $2004^{\mathrm{a}}$

\begin{tabular}{|c|c|c|c|c|c|c|}
\hline & \multirow{2}{*}{$\begin{array}{c}\text { Total } \\
\text { advertising } \\
\text { spend }^{\mathrm{b}}\end{array}$} & \multirow{2}{*}{$\begin{array}{l}\% \text { of GDP } \\
\text { spent on } \\
\text { advertising }\end{array}$} & \multicolumn{4}{|c|}{$\%$ of advertising spent on ${ }^{c}$} \\
\hline & & & magazines & newspapers & radio & television \\
\hline Argentina & 2836 & 2.03 & 6.4 & 25.8 & 4.7 & 63.1 \\
\hline Australia & 6489 & 1.05 & 7.5 & 41.3 & 9.6 & 37.1 \\
\hline Austria & 2652 & .91 & 18.4 & 43.8 & 7.7 & 22.3 \\
\hline Belgium & 3230 & .95 & 12.4 & 31.8 & 9.7 & 38.6 \\
\hline Brazil & 4576 & 1.60 & 8.7 & 17.4 & 4.5 & 64.3 \\
\hline Canada & 7419 & .75 & 7.9 & 37.0 & 13.0 & 35.3 \\
\hline Chile & 592 & .63 & 4.0 & 27.9 & 9.0 & 51.1 \\
\hline Costa Rica & 244 & 1.48 & 6.5 & 25.9 & 17.4 & 43.4 \\
\hline Denmark & 1572 & .66 & 12.6 & 53.7 & 2.4 & 21.2 \\
\hline Finland & 1551 & .83 & 16.1 & 54.3 & 4.3 & 20.1 \\
\hline France & 12178 & .60 & 22.3 & 23.9 & 8.0 & 32.2 \\
\hline Germany & 20277 & .75 & 18.5 & 43.5 & 4.0 & 26.2 \\
\hline Greece & 2012 & .98 & 35.7 & 21.5 & 3.9 & 38.9 \\
\hline Hong Kong & 5056 & 3.07 & 12.1 & 38.8 & 3.8 & 38.2 \\
\hline India & 2627 & .39 & $\mathrm{na}^{\mathrm{d}}$ & na & 1.8 & 41.2 \\
\hline Ireland & 1517 & .84 & 2.0 & 63.0 & 7.4 & 18.6 \\
\hline Italy & 10433 & .64 & 15.7 & 20.5 & 4.8 & 54.2 \\
\hline Japan & 35988 & .76 & 9.4 & 25.1 & 4.2 & 45.7 \\
\hline Kuwait & 382 & .85 & 12.8 & 70.9 & 1.6 & 7.0 \\
\hline Netherlands & 4276 & .74 & 22.7 & 42.7 & 7.1 & 21.6 \\
\hline New Zealand & 1316 & 1.38 & 11.3 & 39.9 & 12.5 & 32.4 \\
\hline Norway & 1357 & .54 & 14.1 & 50.8 & 4.6 & 26.2 \\
\hline Philippines & 2021 & 2.34 & na & na & 17.2 & 72.6 \\
\hline Portugal & 2566 & 1.53 & 10.7 & 22.5 & 5.2 & 54.8 \\
\hline Saudi Arabia & 699 & .31 & 7.9 & 70.8 & 2.9 & 10.6 \\
\hline Singapore & 1203 & 1.13 & 4.6 & 36.4 & 9.3 & 43.7 \\
\hline South Africa & 2194 & 1.09 & 11.9 & 28.0 & 13.6 & 39.4 \\
\hline South Korea & 6415 & .94 & 3.6 & 43.7 & 2.9 & 34.1 \\
\hline Spain & 7483 & .75 & 11.0 & 28.1 & 9.0 & 43.4 \\
\hline Sweden & 2403 & .69 & 11.5 & 51.5 & 2.8 & 21.5 \\
\hline Switzerland & 2906 & .81 & 18.5 & 45.9 & 3.6 & 15.1 \\
\hline Taiwan & 2033 & .63 & 11.9 & 24.3 & 4.8 & 50.1 \\
\hline Thailand & 2045 & 1.25 & 6.8 & 21.0 & 8.3 & 57.0 \\
\hline Turkey & 1307 & .43 & 5.2 & 33.2 & 4.0 & 51.3 \\
\hline United Arab Emirates & 634 & .80 & 17.9 & 54.4 & 1.7 & 19.4 \\
\hline U.K. & 24285 & 1.17 & 14.3 & 38.8 & 4.0 & 30.4 \\
\hline U.S. & 145585 & 1.24 & 10.3 & 30.7 & 12.4 & 38.9 \\
\hline Median & & .84 & 11.5 & 37.0 & 4.8 & 38.2 \\
\hline
\end{tabular}

a Sources: WARC/ZenithOptimedia.

${ }^{\mathrm{b}}$ In millions of U.S. dollars.

${ }^{\mathrm{c}}$ The proportion spent on cinema, outdoor, and Internet is not included, which explains why the percentages do not sum to 100.

${ }^{\mathrm{d}}$ na=not available. 
Table 2: Meta-analysis on co-movement elasticity

\begin{tabular}{|l|cc|ccc|}
\hline \multicolumn{2}{|c|}{} & & \multicolumn{3}{|c|}{ Rosenthal's weighted $Z$ 's ${ }^{1}$} \\
\hline & & & \multicolumn{3}{|c|}{ Co-movement $>\mathbf{1}$} \\
\cline { 4 - 7 } Overall & 118 & 1.39 & 73 & 6.88 & $<.01$ \\
\cline { 4 - 6 } Magazines & 30 & 1.70 & 20 & 5.72 & $<.01$ \\
Newspapers & 35 & 1.54 & 24 & 6.52 & $<.01$ \\
Radio & 17 & .79 & 8 & -1.34 & .91 \\
Television & 36 & 1.27 & 21 & 1.68 & .05 \\
\hline
\end{tabular}

${ }^{1}$ The meta-analysis reports Z-values obtained by the Method of Adding Weighted Z's (Rosenthal 1991).

Table 3: Explaining variability in advertising co-movement elasticities across countries

\begin{tabular}{|c|c|c|c|c|}
\hline Predictor & Expected & $\begin{array}{l}\text { Unstandardized } \\
\text { coefficient }^{1}\end{array}$ & $t$-value & $\begin{array}{l}\text { Effect size } \\
\text { (Cohen's d) }\end{array}$ \\
\hline Constant & & $1.41^{\mathrm{c}}$ & 1.72 & \\
\hline \multicolumn{5}{|l|}{ Cultural factors } \\
\hline Long-term orientation & - & $-.02^{b}$ & -1.81 & .36 \\
\hline Power distance & - & $-.02^{b}$ & -2.07 & .41 \\
\hline Uncertainty avoidance & + & $.02^{\mathrm{a}}$ & 2.79 & .55 \\
\hline Collectivism & + & -.01 & -.96 & n.s. \\
\hline \multicolumn{5}{|l|}{ Control variables } \\
\hline Stock market pressure & & $.82^{\mathrm{b}}$ & 2.32 & .46 \\
\hline $\begin{array}{l}\text { Importance of foreign- } \\
\text { owned subsidiaries }\end{array}$ & & $-.08^{\mathrm{b}}$ & -2.13 & .42 \\
\hline Real income per capita & & .00 & .15 & n.s. \\
\hline Magazines & & $.43^{\mathrm{b}}$ & 2.46 & .49 \\
\hline Newspapers & & .25 & 1.55 & n.s. \\
\hline Radio & & $-.45^{\mathrm{b}}$ & -2.07 & .41 \\
\hline Africa & & -1.25 & -1.30 & n.s. \\
\hline Asia & & $1.99^{\mathrm{a}}$ & 2.89 & .57 \\
\hline Europe & & $.89^{\mathrm{b}}$ & 2.21 & .44 \\
\hline Oceania & & .08 & .12 & n.s. \\
\hline South America & & $1.95^{\mathrm{a}}$ & 2.96 & .59 \\
\hline $\mathbf{N}$ & & 118 & & \\
\hline $\mathbf{R}^{2}$ & & $35 \%$ & & \\
\hline
\end{tabular}

${ }^{\mathrm{a}} p<.01 ;{ }^{\mathrm{b}} p<.05 ;{ }^{\mathrm{c}} p<.10$.

${ }^{1} p$-values are one-sided for directional hypotheses, two-sided otherwise (Ferguson 1981). 
Table 4: Social and managerial implications of advertising's sensitivity to business cycles

\begin{tabular}{|c|c|c|c|c|c|c|c|c|c|c|c|c|}
\hline & \multicolumn{4}{|c|}{$\begin{array}{l}\text { Long-run growth of advertising } \\
\text { industry } \\
(\mathrm{N}=37)\end{array}$} & \multicolumn{4}{|c|}{$\begin{array}{l}\text { Long-run growth of private-label } \\
\text { share } \\
(\mathrm{N}=30)\end{array}$} & \multicolumn{4}{|c|}{$\begin{array}{l}\text { Long-run growth of firm share } \\
\text { price } \\
(\mathrm{N}=26)\end{array}$} \\
\hline & $\operatorname{coeff}^{1}$ & $t$-value ${ }^{2}$ & $p$-value ${ }^{3}$ & $\begin{array}{c}\text { effect } \\
\text { size }^{4}\end{array}$ & coeff & $t$-value & $p$-value & $\begin{array}{c}\text { effect } \\
\text { size }\end{array}$ & coeff & $t$-value & $p$-value & $\begin{array}{c}\text { effect } \\
\text { size }\end{array}$ \\
\hline Constant & 4.20 & 2.83 & $<.01$ & & 11.67 & 2.88 & $<.01$ & & 5.00 & 4.24 & $<.01$ & \\
\hline National co-movement elasticity & -1.09 & -2.09 & .04 & .72 & 2.84 & 1.67 & .11 & .64 & & & & \\
\hline Real GDP growth & 107.28 & 2.65 & .01 & .91 & -185.20 & -1.77 & .09 & .68 & & & & \\
\hline Firm co-movement elasticity & & & & & & & & & -.53 & -1.91 & .07 & .78 \\
\hline
\end{tabular}

${ }^{1}$ represent unstandardized regression coefficients.

${ }^{2} t$-values based on robust standard errors (see Nijs, Srinivasan, and Pauwels 2007).

3 all $p$-values are two-sided

${ }^{4}$ effect size $=$ Cohen's d. 
Figure 1: Cyclical sensitivity of advertising spending per quartile
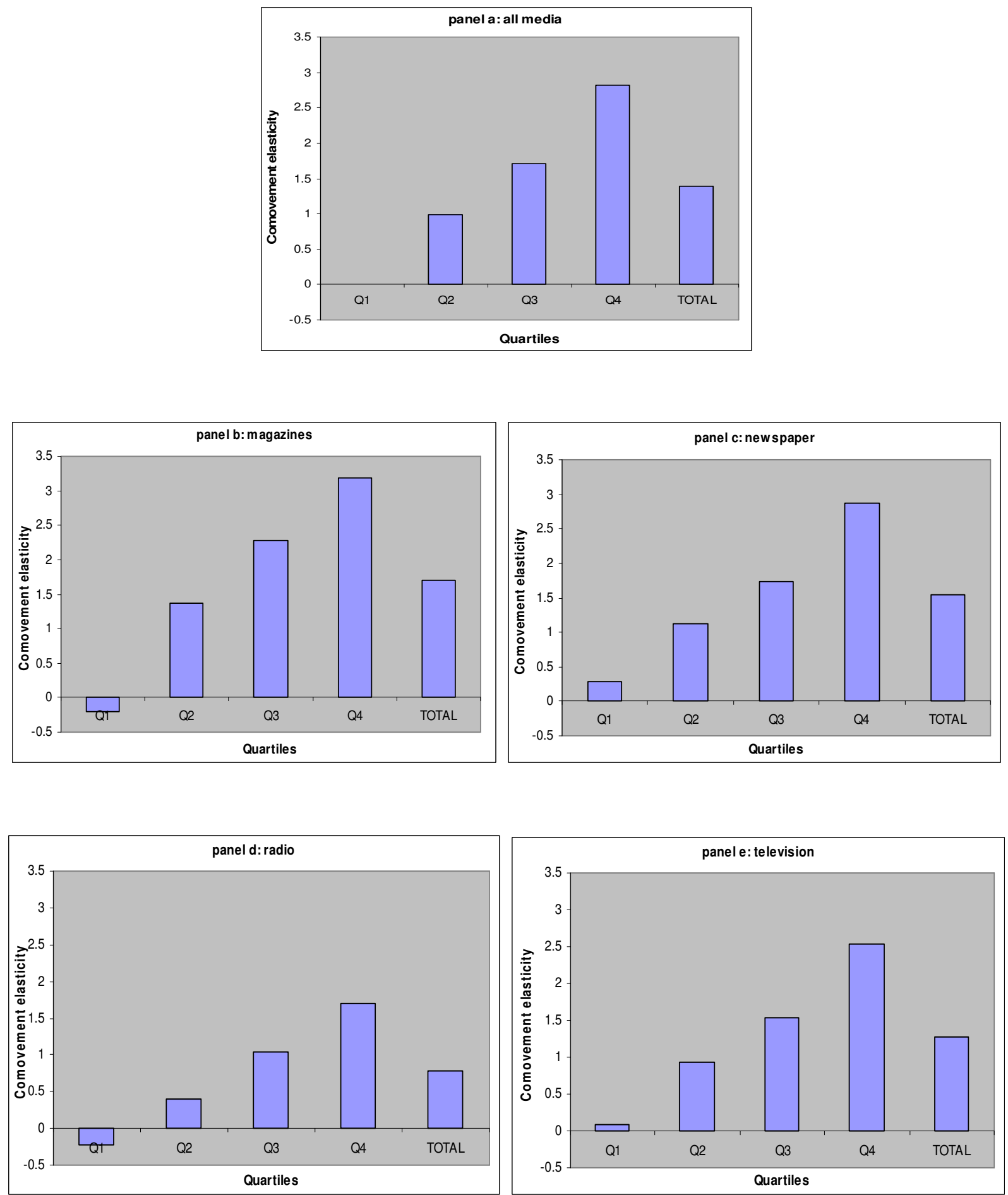